\title{
Subtype specific genetic associations for juvenile idiopathic arthritis: ERAP1 with the enthesitis related arthritis subtype and IL23R with juvenile psoriatic arthritis
}

Anne Hinks ${ }^{1 *}$, Paul Martin ${ }^{1}$, Edward Flynn ${ }^{1}$, Steve Eyre ${ }^{1}$, Jon Packham², Childhood Arthritis Prospective Study (CAPS), BSPAR study group, Anne Barton', Jane Worthington', Wendy Thomson'

\begin{abstract}
Introduction: Juvenile idiopathic arthritis (JIA) is an umbrella term for all chronic childhood arthropathies and can be divided into seven subtypes. It includes the enthesitis related arthritis (ERA) subtype which displays symptoms similar to ankylosing spondylitis (AS) and juvenile-onset psoriatic arthritis which has similarities to psoriatic arthritis (PsA) and psoriasis (Ps). We, therefore, hypothesized that two well-established susceptibility loci for AS and Ps, ERAP1 and IL23R, could also confer susceptibility to these JIA subtypes.

Methods: Single nucleotide polymorphisms (SNPS) in ERAP1 (rs30187) and IL23R (rs11209026) were genotyped in JIA cases $(n=1,054)$ and healthy controls $(n=5,200)$. Genotype frequencies were compared between all JIA cases and controls using the Cochrane-Armitage trend test implemented in PLINK. Stratified analysis by ILAR subtype was performed.

Results: The ERA subtype showed strong association with ERAP1 SNP ( $P$ trend $=0.005)$. The IL23R SNP showed significant association in the PSA subtype $(P$ trend $=0.04)$. The SNPs were not associated with JIA overall or with any other subtype.

Conclusions: We present evidence for subtype specific association of the ERAP1 gene with ERA JIA and the IL23R gene with juvenile-onset PsA. The findings will require validation in independent JIA datasets. These results suggest distinct pathogenic pathways in these subtypes.
\end{abstract}

\section{Introduction}

There is now strong evidence supporting the hypothesis of common autoimmune genetic susceptibility loci [1]. Ankylosing spondylitis (AS), psoriasis (Ps) and psoriatic arthritis (PsA) are a group of autoimmune diseases which share some clinical features and some overlapping susceptibility loci such as endoplasmic reticulum aminopeptidase 1 (ERAP1) (formerly known as ARTS1) [2,3] and the interleukin 23 receptor $(I L 23 R)[2,4,5]$.

Juvenile idiopathic arthritis (JIA) is an umbrella term for all chronic childhood arthropathies and can be classified into seven subtypes on the basis of features present in the

\footnotetext{
* Correspondence: a.m.hinks@manchester.ac.uk

${ }^{1}$ Arthritis Research UK Epidemiology Unit, Manchester Academic Health Science Centre, Stopford Building, Oxford Road, The University of Manchester, Manchester, M13 9PT, UK

Full list of author information is available at the end of the article
}

first six months of disease [6]. It includes the enthesitis related arthritis (ERA) subtype, which displays symptoms similar to AS and juvenile onset psoriatic arthritis, which has similarities to psoriatic arthritis and psoriasis. We have, therefore, hypothesized that the two well-established susceptibility loci, ERAP1 and IL23R, also confer susceptibility to these JIA subtypes. To this end the most associated single nucleotide polymorphism (SNP) within each of these genes has been selected for genotyping across all JIA and also analysed stratified by ILAR subtype.

\section{Materials and methods}

Subjects

For the analysis of the ERAP1 SNP, DNA was available for 1,054 UK Caucasian JIA patients (332 males, 715 females) as previously described [7]. JIA cases were

\section{C) Biomed Central}


classified according to ILAR criteria [6]. The numbers genotyped per ILAR subgroup were: Systemic onset $(n=164)$, persistent oligoarthritis $(n=297)$, extended oligoarthritis ( $\mathrm{n}=147)$, rheumatoid factor (RF) negative polyarticular JIA ( $n=215)$, RF positive polyarticular JIA $(n=68)$, enthesitis related JIA $(\mathrm{n}=63)$, psoriatic JIA $(\mathrm{n}=76)$ and unclassified $(\mathrm{n}=24)$. For the analysis of the IL23R SNP, there were an additional 190 JIA cases available, making a total of 1,244 JIA cases. The numbers genotyped per ILAR subgroup were: Systemic onset $(n=179)$, persistent oligoarthritis $(n=380)$, extended oligoarthritis $(n=159)$, rheumatoid factor (RF) negative polyarticular JIA ( $\mathrm{n}=$ $259)$, RF positive polyarticular JIA $(n=76)$, enthesitis related JIA $(\mathrm{n}=74)$, psoriatic JIA $(\mathrm{n}=93)$ and unclassified $(n=24)$. All individuals were recruited with ethical approval and provided informed consent (North-West Multi-Centre Research Ethics Committee (MREC 99/8/ 84) and the University of Manchester Committee on the Ethics of Research on Human Beings).

The control genotyping data were extracted from the Wellcome Trust case control consortium 2 (WTCCC2) European Genome-phenome Archive (EGA) website [8], both SNPs had been genotyped on the Illumina platform $(n=5,200)$.

\section{SNP selection}

SNPs in IL23R (rs11209026) and ERAP1 (rs30187) previously associated with AS and Ps were selected for genotyping.

\section{Genotyping}

All SNPs were genotyped, in UK JIA cases, using the Sequenom iPlex ${ }^{\circledR}$ MassARRAY platform according to manufacturer's instructions (Sequenom, San Diego, CA, USA [9]). A 90\% sample quality control rate and $90 \%$ genotyping success rate was imposed on the analysis.

\section{Statistical analysis}

Power calculations were performed using QUANTO [10] based on the effect sizes reported in previous studies of these SNPs in AS $[2,11]$. Calculations assumed a logadditive model and an alpha value of 0.05. Genotype and allele frequencies were compared between cases with JIA and controls using STATA version 9 SE (StataCorp, College Station, Texas, USA) and PLINK [12]. Associations were expressed as odds ratios (ORs) and 95\% confidence intervals (CIs). There was a strong prior hypothesis that these SNPs would be associated with the ERA and PsA subtypes of JIA; therefore, we performed stratified analysis by ILAR subtype.

\section{Results}

SNPs were in Hardy-Weinberg equilibrium $(P>0.05)$ in the control cohort.

Neither rs30187 in ERAP1 nor rs11209026 in IL23R were significantly associated with the total JIA dataset ( $P$ trend $=0.73, \mathrm{OR}=1.0395 \% \mathrm{CI} 0.92$ to 1.14 and $P$ trend $=0.46, \mathrm{OR}=0.9395 \% \mathrm{CI} 0.78$ to 1.12 , respectively).

After stratification by ILAR subtype (Table 1) the ERA subtype showed strong association with the ERAP1 SNP $(P$ trend $=0.005$, OR $=1.6995 \%$ CI 1.17 to 2.44$)$. For the IL23R SNP there was significant association in the psoriatic arthritis subtype $(P$ trend $=0.04, \mathrm{OR}=0.495 \%$ CI 0.16 to 0.98 ) and a trend towards association in the enthesitis related subtype $(P$ trend $=0.15$, OR $=0.52$ $95 \%$ CI 0.21 to 1.28 ). For both SNPs the association is in the same direction as in the original studies.

Table 1 Association analysis of IL23R (rs11209026) and ERAP1 (rs30187) SNPs in all JIA and stratified by subtype

\begin{tabular}{|c|c|c|c|c|c|c|c|c|}
\hline \multirow[b]{2}{*}{ ILAR subtype } & \multicolumn{4}{|c|}{ IL23R (rs11209026) } & \multicolumn{4}{|c|}{ ERAP1 (rs30187) } \\
\hline & $\begin{array}{l}\text { MAF } \\
\text { Cases }\end{array}$ & $\begin{array}{l}\text { MAF } \\
\text { Controls }\end{array}$ & $P$ Trend & OR 95\% Cl & $\begin{array}{l}\text { MAF } \\
\text { Cases }\end{array}$ & $\begin{array}{l}\text { MAF } \\
\text { Controls }\end{array}$ & $P$ Trend & OR $95 \% \mathrm{Cl}$ \\
\hline All JIA & 0.06 & 0.07 & 0.46 & $\begin{array}{r}0.93 \\
\text { (0.78 to } 1.12\end{array}$ & 0.34 & 0.33 & 0.65 & $\begin{array}{r}1.02 \\
\text { (0.92 to } 1.13\end{array}$ \\
\hline Systemic & 0.08 & 0.07 & 0.44 & $\begin{array}{r}1.17 \\
\text { (0.78 to } 1.76)\end{array}$ & 0.35 & 0.33 & 0.56 & $\begin{array}{r}1.07 \\
\text { (0.85 to } 1.36)\end{array}$ \\
\hline Persistent oligoarthritis & 0.07 & 0.07 & 0.85 & $\begin{array}{r}1.03 \\
\text { (0.77 to } 1.39 \text { ) }\end{array}$ & 0.31 & 0.33 & 0.31 & $\begin{array}{r}0.91 \\
\text { (0.76 to } 1.09 \text { ) }\end{array}$ \\
\hline Extended oligoarthritis & 0.07 & 0.07 & 0.65 & $\begin{array}{r}1.11 \\
(0.71 \text { to } 1.72)\end{array}$ & 0.34 & 0.33 & 0.84 & $\begin{array}{r}1.03 \\
\text { (0.80 to } 1.32 \text { ) }\end{array}$ \\
\hline RF negative polyarthritis & 0.06 & 0.07 & 0.5 & $\begin{array}{r}0.88 \\
\text { (0.6 to } 1.29 \text { ) }\end{array}$ & 0.30 & 0.33 & 0.19 & $\begin{array}{r}0.86 \\
(0.70 \text { to } 1.07)\end{array}$ \\
\hline RF positive oligoarthritis & 0.07 & 0.07 & 0.93 & $\begin{array}{r}0.97 \\
\text { (0.49 to } 1.91 \text { ) }\end{array}$ & 0.39 & 0.33 & 0.22 & $\begin{array}{r}1.26 \\
\text { (0.87 to } 1.82 \text { ) }\end{array}$ \\
\hline Enthesitis related arthritis & 0.04 & 0.07 & 0.15 & $\begin{array}{r}0.52 \\
\text { (0.21 to } 1.28)\end{array}$ & 0.46 & 0.33 & 0.005 & $\begin{array}{r}1.69 \\
(1.178 \text { to } 2.44)\end{array}$ \\
\hline Psoriatic arthritis & 0.03 & 0.07 & 0.04 & $\begin{array}{r}0.4 \\
(0.16 \text { to } 0.98)\end{array}$ & 0.38 & 0.33 & 0.21 & (0.88 to 1.74$)$ \\
\hline
\end{tabular}

$\mathrm{Cl}$, confidence interval; ERAP1, endoplasmic reticulum aminopeptidase 1; IL23R, interleukin 23 receptor; JIA, juvenile idiopathic arthritis; MAF, minor allele frequency; $O R$, odds ratio. 


\section{Discussion}

Investigating the genetic susceptibility loci identified for clinically related autoimmune diseases has been a very successful strategy in the search for novel JIA susceptibility loci [7]. Using this approach in this study we have identified subtype specific effects in JIA.

We found strong association of the ERA subtype with the ERAP1 SNP. There was no significant association with any other subtype. However, it should be noted that the individual subtypes had between 16 and $54 \%$ power to detect an association. The ERAP1 variant, rs 30187 , is a non-synonymous SNP, K528R, located in exon 6 of the gene previously associated with AS [2], with Ps [3] and PsA (personal communication, Anne Barton), and also with type 1 diabetes [13]. In a recent fine-mapping study, multiple SNPs across the region were associated with AS and they were not able to identify the causal marker from the genetic data due to the high LD across the region. Imputation analysis in this dataset found strong associations for imputed SNPs, including some SNPs in regulatory regions which may be good candidates for the causal SNP. Further studies on how these SNPs affect expression of ERAP1 are now required [11].

ERAP1 encodes a multifunctional aminopeptidase, but its role in the pathogenesis in any of the associated diseases has yet to be determined (reviewed in [14]). It may play a role in trimming peptides, in the endoplasmic reticulum, for binding to HLA class I molecules where they are transported to the cell surface for presentation to $\mathrm{T}$ cells. Alternatively it may be important through its function in cleaving pro-inflammatory cytokine receptors, such as tumour necrosis factor receptor 1 (TNFR1) to generate soluble TNFR1. It is also thought to play a role in the cleavage of interleukin 1 receptor 2 (IL1R2) and interleukin 6 receptor alpha (IL6R $\alpha$ ), leading to increased soluble IL1R2 and IL6R $\alpha$.

The IL23R SNP showed significant association in the PsA subtype and a trend towards association in the ERA subtype, with similar effect sizes in both subtypes, suggesting that the lack of significant association in the ERA subtype of JIA may just be due to a lack of power (this subtype had $37 \%$ power to detect an association). IL23R shows association not only with AS, Ps, PsA $[2,4,5]$, but also with inflammatory bowel disease [15] and paediatric Crohn's disease [16]. The SNP rs11209026 appears to be the primary associated polymorphism [17]. It is a non-synonymous SNP, Q381R, located in exon 5 of the gene. In all cases the minor allele is associated with protection for developing the disease. The association of $I L 23 R$ with these conditions suggests that the T Helper 17 (TH17) pathway may be involved in disease pathogenesis. IL23R is also expressed on other immunological cell types such as macrophages, natural killer cells and microglia and it is not yet determined which cell type is affected by the IL23R variant. Therapeutic approaches to inhibiting TH17 cells are now being investigated that could be useful in the treatment of juvenile-onset PsA and the ERA subtype of JIA.

To date it has been very difficult to identify ILAR subtype specific effects in JIA due to small sample sizes and the inevitable loss of power that this entails as well as the issues of multiple testing. In this case there was a strong prior hypothesis that ERAP1 and IL23R confer susceptibility to particular subtypes. However, the results will require validation in independent datasets. The lack of association across the other subtypes will also require further investigation. For the ERAP1 SNP we had between 16 and $54 \%$ power to detect an association across the subtypes and for the IL23R SNP we had between 37 and $95 \%$ power to detect an association. The search for subtype specific effects in JIA is imperative because it will aid in the refinement of the JIA classification, potentially lead to a better understanding of subtype specific disease pathogenesis, and ultimately to the development of more targeted therapies for the specific subtypes of JIA. It may also be relevant for evaluating prognosis. Not all children with ERA will go on to have the complete AS phenotype and it may be that carriage of these risk alleles predict progression to axial involvement and eventual ankylosis [18].

\section{Conclusions}

We present evidence for subtype specific association of the IL23R gene with juvenile-onset PsA and ERAP1 gene with the ERA subtype of JIA. These results suggest distinct pathogenic pathways in these subtypes.

\section{Abbreviations}

AS: ankylosing spondylitis; Cl: Confidence interval; EGA: European Genomephenome Archive; ERA: enthesitis related arthritis; ERAP1: endoplasmic reticulum aminopeptidase 1; HWE: Hardy-Weinberg equilibrium; IL1R2: interleukin 1 receptor 2; IL6Ra: interleukin 6 receptor alpha; IL23R: interleukin 23 receptor; ILAR: International League of Associations for Rheumatology; JIA: juvenile idiopathic arthritis; OR: odds ratio; PsA: psoriatic arthritis; Ps: psoriasis; SNP: single nucleotide polymorphism; TH17: T helper 17; TNFR1: tumour necrosis factor receptor 1; WTCCC2: Wellcome Trust Case Control Consortium 2.

\section{Acknowledgements}

This work was supported by Arthritis Research UK: AR UK grant reference no: 17552.

This study makes use of data generated by the Wellcome Trust Case-Control Consortium 2. A full list of the investigators who contributed to the generation of the data is available from [19]. Funding for the project was provided by the Wellcome Trust under award 085475.

Childhood Arthritis Prospective Study (CAPS): Eileen Baildam, Lynsey Brown, Joanne Buckley, Alice Chieng, Joyce Davidson, Michael Eltringham, Helen Foster, Mark Friswell, Janet Gardner-Medwin, Paul Gilbert, Kimme Hyrich, Julie Jones, Sham Lal, Mark Lay, Carol Lydon, Alexandra Meijer, Vicki Price, Jane Sim, Maureen Todd, Peter Ward, Lucy Wedderburn. British Society of Paediatric and Adolescent Rheumatology (BSPAR) study group: M. Abinum, MD, M. Becker, MD, A. Bell, MD, A. Craft, MD, E. Crawley, MD, J. David, MD, H. Foster, MD, J. Gardener-Medwin, MD, J. Griffin, 
MD, A. Hall, MD, M. Hall, MD, A. Herrick, MD, P. Hollingworth, MD, L. Holt, MD, S. Jones, MD, G. Pountain, MD, C. Ryder, MD, T. Southwood, MD, I. Stewart, MD, H. Venning. L. Wedderburn, MD, P. Woo, MD, and S. Wyatt, MD.

\section{Author details}

${ }^{1}$ Arthritis Research UK Epidemiology Unit, Manchester Academic Health Science Centre, Stopford Building, Oxford Road, The University of Manchester, Manchester, M13 9PT, UK. ${ }^{2}$ Haywood Hospital, University Hospital of North Staffordshire, High Lane, Stoke on Trent, Staffordshire, ST4 7LN, UK.

\section{Authors' contributions}

$A H, W T, S E, J W$ and $A B$ conceived the study. PM and EF performed the genotyping; $\mathrm{AH}$ undertook the statistical analysis. JP, CAPs and the BSPAR study group consortia provided samples. $A H, W T$ and $A B$ drafted the manuscript and all authors contributed to and approved the final version.

\section{Competing interests}

The authors declare that they have no competing interests.

Received: 12 October 2010 Revised: 16 December 2010

Accepted: 31 January 2011 Published: 31 January 2011

\section{References}

1. Lettre G, Rioux JD: Autoimmune diseases: insights from genome-wide association studies. Hum Mol Genet 2008, 17:R116-R121.

2. Burton PR, Clayton DG, Cardon LR, Craddock N, Deloukas P, Duncanson A, Kwiatkowski DP, McCarthy MI, Ouwehand WH, Samani NJ, Todd JA, Donnelly P, Barrett JC, Davison D, Easton D, Evans DM, Leung HT, Marchini JL, Morris AP, Spencer CC, Tobin MD, Attwood AP, Boorman JP, Cant B, Everson U, Hussey JM, Jolley JD, Knight AS, Koch K, Meech E, et al: Association scan of 14,500 nonsynonymous SNPs in four diseases identifies autoimmunity variants. Nat Genet 2007, 39:1329-1337.

3. Strange A, Capon F, Spencer CC, Knight J, Weale ME, Allen MH, Barton A, Band G, Bellenguez C, Bergboer JG, Blackwell JM, Bramon E, Bumpstead SJ, Casas JP, Cork MJ, Corvin A, Deloukas P, Dilthey A, Duncanson A, Edkins S, Estivill X, Fitzgerald O, Freeman C, Giardina E, Gray E, Hofer A, Huffmeier U, Hunt $\mathrm{SE}$, Irvine $\mathrm{AD}$, Jankowski J, et al: A genome-wide association study identifies new psoriasis susceptibility loci and an interaction between HLA-C and ERAP1. Nat Genet 2010, 42:985-990.

4. Cargill M, Schrodi SJ, Chang M, Garcia VE, Brandon R, Callis KP, Matsunami N, Ardlie KG, Civello D, Catanese JJ, Leong DU, Panko JM, McAllister LB, Hansen CB, Papenfuss J, Prescott SM, White TJ, Leppert MF, Krueger GG, Begovich AB: A large-scale genetic association study confirms IL12B and leads to the identification of IL23R as psoriasis-risk genes. Am J Hum Genet 2007, 80:273-290.

5. Filer C, Ho P, Smith RL, Griffiths C, Young HS, Worthington J, Bruce IN, Barton A: Investigation of association of the IL12B and IL23R genes with psoriatic arthritis. Arthritis Rheum 2008, 58:3705-3709.

6. Petty RE, Southwood TR, Manners P, Baum J, Glass DN, Goldenberg J, He X, Maldonado-Cocco J, Orozco-Alcala J, Prieur AM, Suarez-Almazor ME, Woo P: International League of Associations for Rheumatology classification of juvenile idiopathic arthritis: second revision, Edmonton, 2001. J Rheumatol 2004, 31:390-392.

7. Hinks A, Eyre S, Ke X, Barton A, Martin P, Flynn E, Packham J, Childhood Arthritis Prospective Study (CAPS); UKRAG Consortium; BSPAR Study Group, Worthington J, Thomson W: Overlap of disease susceptibility loci for rheumatoid arthritis (RA) and juvenile idiopathic arthritis (JIA). Ann Rheum Dis 2010, 69:1049-1053.

8. The European Genome-phenome Archive. [http://www.ebi.ac.uk/ega/ page.php].

9. Sequenom. [http://www.sequenom.com/]

10. QUANTO. [http://hydra.usc.edu/gxe/].

11. Harvey D, Pointon JJ, Evans DM, Karaderi T, Farrar C, Appleton LH, Sturrock RD, Stone MA, Oppermann U, Brown MA, Wordsworth BP: Investigating the genetic association between ERAP1 and ankylosing spondylitis. Hum Mol Genet 2009, 18:4204-4212.

12. Purcell $S$, Neale B, Todd-Brown K, Thomas L, Ferreira MA, Bender D, Maller J, Sklar P, De Bakker PI, Daly MJ, Sham PC: PLINK: a tool set for wholegenome association and population-based linkage analyses. Am J Hum Genet 2007, 81:559-575.
13. Fung EY, Smyth DJ, Howson JM, Cooper JD, Walker NM, Stevens H, Wicker LS, Todd JA: Analysis of 17 autoimmune disease-associated variants in type 1 diabetes identifies 6q23/TNFAIP3 as a susceptibility locus. Genes Immun 2009, 10:188-191.

14. Haroon N, Inman RD: Endoplasmic reticulum aminopeptidases: Biology and pathogenic potential. Nat Rev Rheumatol 2010, 6:461-467.

15. Duerr RH, Taylor KD, Brant SR, Rioux JD, Silverberg MS, Daly MJ, Steinhart AH, Abraham C, Regueiro M, Griffiths A, Dassopoulos T, Bitton A, Yang H, Targan S, Datta LW, Kistner EO, Schumm LP, Lee AT, Gregersen PK, Barmada MM, Rotter Jl, Nicolae DL, Cho JH: A genome-wide association study identifies IL23R as an inflammatory bowel disease gene. Science 2006, 314:1461-1463.

16. Dubinsky MC, Wang D, Picornell $Y$, Wrobel I, Katzir L, Quiros A, Dutridge $D$, Wahbeh G, Silber G, Bahar R, Mengesha E, Targan SR, Taylor KD, Rotter Jl: IL-23 receptor (IL-23R) gene protects against pediatric Crohn's disease. Inflamm Bowel Dis 2007, 13:511-515.

17. Brown MA: Progress in spondylarthritis. Progress in studies of the genetics of ankylosing spondylitis. Arthritis Res Ther 2009, 11:254.

18. Colbert RA: Classification of juvenile spondyloarthritis: Enthesitis-related arthritis and beyond. Nat Rev Rheumatol 2010, 6:477-485.

19. Wellcome Trust Case Control Consortium. [http://www.wtccc.org.uk].

\section{doi:10.1186/ar3235}

Cite this article as: Hinks et al:: Subtype specific genetic associations for juvenile idiopathic arthritis: ERAP1 with the enthesitis related arthritis subtype and IL23R with juvenile psoriatic arthritis. Arthritis Research \& Therapy 2011 13:R12.

\section{Submit your next manuscript to BioMed Central and take full advantage of:}

- Convenient online submission

- Thorough peer review

- No space constraints or color figure charges

- Immediate publication on acceptance

- Inclusion in PubMed, CAS, Scopus and Google Scholar

- Research which is freely available for redistribution 